\title{
Research on Flame Retardant Plywood with Different Flame Retardants $^{1}$
}

\author{
Yang $\mathrm{LIU}^{2} \cdot$ Jun-xian $\mathrm{XU}^{2} \cdot$ Ming-yu WEN(D) ${ }^{2, \dagger} \cdot$ Hee-Jun PARK(D) ${ }^{3, \dagger}$ • \\ Jia-zhi $\mathrm{ZHU}^{4} \cdot$ Yu-nan $\mathrm{LIU}^{5}$
}

\begin{abstract}
The flame retardancy of plywood should be improved as much as possible while minimizing the impact on the bonding strength of plywood. Six commercial flame retardants and three laboratory synthesized phosphorous nitrogen flame retardants were selected. $E_{0}, E_{1}$ and $E_{2}$ grade commercial formaldehyde resins (UF) were applied in this study to evaluate the effect of different flame retardants on the curing time of resin, bonding strength, flame retardant performance, and formaldehyde emission of plywood. The results show that the effect of the addition of different flame retardants on the bonding strength of plywood gradually decreased with the increase of the formaldehyde molar ratio of the resin. The effect of flame retardants on the curing time of UF gradually decreased as the mole ratio of formaldehyde increasing, while the amount of formaldehyde emission varied according to the content of formaldehyde in the flame retardant. Compared with plywood without flame retardant, flame retardant of plywood added with phosphorous nitrogen flame retardant was improved.
\end{abstract}

Keywords: flame retardant plywood, phosphorous nitrogen flame retardant, curing time, urea-formaldehyde resins, bonding strength, formaldehyde emission

\section{INTRODUCTION}

During the recent ten years, China became the largest exporter of wood products, especially plywood and furniture (Tan, 2020). Plywood occupies the leading position of China's wood-based panels, and its output and market share rank first (Qin et al., 2020). Urea-formaldehyde (UF) resin is the most widely used as an adhesive for plywood. Therefore, UF resin is considered to be one of the most important wood adhesives (Jeong et al., 2019). Because plywood can better retain the natural pattern of wood (Cheng, 2008),

${ }^{1}$ Date Received August 31, 2021, Date Accepted November 19, 2021

2 Department of Wood Material Science and Engineering Key Laboratory, College of Materials Science and Engineering, Beihua University, Jilin Province, Jilin-city, 132013, China

${ }^{3}$ Department of Housing Environmental Design, and Research Institute of Human Ecology, College of Human Ecology, Jeonbuk National University, Jeonbuk 54896, Republic of Korea

${ }^{4}$ Qingdao Water Consservancy Survey and Design Institute Co. Ltd., Shandong Province, Jinan-city, 250000, China

${ }^{5}$ Department of Furniture Design and Engineering, College of Chemistry and Materials, Zhejiang A\&F University, Zhejiang Province, Hangzhou, 310000, China

$\dagger$ Corresponding author: Hee-Jun PARK (e-mail: phjun@jbnu.ac.kr, ORCID: 0000-0002-7452-227X) and Ming-yu WEN (e-mail: jlwenmingyu@163.com, ORCID:000-0001-8684-8456) 
it is widely used in interior construction, such as the lamination of engineered floors (Lubis et al., 2019). According to the Chinese national standard GB 8624-2012 "Classification for burning behavior of building materials and products", untreated plywood is classified as $\mathrm{B}_{2}$ combustible wood material (Chen et al., 2020). The more widely used, the greater the potential safety hazard. Therefore, it is necessary to prepare plywood to ensure the safety of people's property. China has issued relevant national standards such as: GB 50016-2014 "Code for fire protection design of nuildings", which clearly stipulates that the proportion of non-combustible or non-combustible materials in building materials must reach $80 \%$; GB 50222-2017 "Code for fire prevention in design of interior decoration of buildings" clearly that all wood used in buildings must reach the flame-retardant level.

There are usually three methods to improve the flame retardancy of plywood: chemical impregnation of veneer (Ling et al., 2018; Park et al., 2020), adding an appropriate amount of flame retardant to the adhesive (Wang et al., 2018; Wen et al., 2020) and flame retardant coating (Wang and Zhao, 2018; Park et al., 2021). In general, for the second method, the addition of flame retardants will inevitably affect the curing time and formaldehyde emission, and will reduce the bonding strength of the adhesive (Yan et al., 2018). Therefore, it is particularly important to choose a suitable flame retardant.

Flame retardants mainly include phosphorus flame retardants, inorganic flame retardants, halogen flame retardants, and nitrogen flame retardants. At present, the hazardous halogen flame retardants and phosphorus flame retardants still occupy the mainstream (Wang et al., 2016). Among them, inorganic flame retardants have high moisture absorption and poor leaching resistance, and cannot be used in environments with high humidity (LeVan et al., 1990; Winandy et al., 1995). Inorganic phosphorus flame retardants mainly include ammonium polyphosphate (APP), ammonium phosphate, etc. These flame retardants are cheap and soluble in water. They are mostly used as additive flame retardants. They have high flame retardant efficiency and ecological environment protection advantages ( $\mathrm{Lu}$ et al., 2002).

Because phosphorus has multiple oxidation states and does not release toxic substances during the combustion process and the manufacturing cost is low, this makes the range of phosphorus-containing flame retardants very wide, and it has gradually become a substitute for halogen flame retardant (Qu et al., 2020). Nitrogen-based flame retardants mainly improve the flame retardancy of polymers by reducing the concentration of combustible gases during the combustion process or generating more stable condensed phases (Wang et al., 2005). Phosphorus-nitrogen synergistic flame retardant refers to a type of flame retardant containing $\mathrm{P}$ and $\mathrm{N}$ flame retardant elements in the system. Nitrogen-containing compounds release incombustible gases during the thermal decomposition process, and when there is an acid source (phosphorus-containing compound). Under the circumstances, the carbon layer expands to form a layer with a certain thickness, which can better isolate the transfer of heat and greatly improve the flame retardant efficiency (Pan et al., 2019). Combining P, N and $\mathrm{Si}$ elements to synthesize a new type of $\mathrm{P} / \mathrm{N} / \mathrm{Si}$ ternary flame retardant with good flame retardant performance and good char-forming effect have been used for flame retardant treatment of epoxy resin (Qian et al., 2014), cotton fabric (Yang et al., 2012; Wang et al., 2016), etc.. With compounds containing such structures, it is easy to form an inorganic oxygen-insulating and heat-insulating protective layer containing $\mathrm{Si}-\mathrm{O}-\mathrm{Si}$ or $\mathrm{Si}-\mathrm{C}$ at high temperatures, thereby helping to improve the flame retardancy of the finished compound (Qian et al., 2013; Dou et al., 2016). A bisDopo- $\mathrm{NH}_{2}$-POSS flame retardant is one kind of 
P-N-Si flame retardant with Si-O-Si structure was synthesized in our lab. In addition, phosphorus and nitrogen flame retardants were also prepared from the reaction of urea (U) / melamine (M) and Pyrovatex CP as raw materials (abbreviated as UCPR and MCPR).

In this study, several different phosphorous nitrogen flame retardants (six kinds commercial and three kinds laboratory made (bisDopo- $\mathrm{NH}_{2}$-POSS (BDNP), UCPR and MCPR) were mixed with commercial UF resin ( $\mathrm{E}_{0}, \mathrm{E}_{1}$ and $\mathrm{E}_{2}$ grade of GB 18580-2001 criterion) at 5 wt.\% based on liquid UF resin, and three-layer flame retardant plywood was prepared by hot pressing. Through the determination of the plywood bonding strength, formaldehyde emission and flame retardant performance, the influence of different flame retardants on the plywood was analyzed and discussed. It provides a new guiding route for the application of flame retardant plywood.

\section{MATERIALS and METHODS}

\subsection{Materials}

Poplar veneer with a moisture content (MC) of $10 \%-12 \%$ and dimensions of $1.2 \mathrm{~mm} \times 300 \mathrm{~mm} \times$ $300 \mathrm{~mm}$, originating from northeast China, was used. $E_{0}, E_{1}$ and $E_{2}$ grade urea-formaldehyde resin were provided by Jilin Penghong Wood Industry Co., Ltd., with 45\% solids content and 6.5-7.5 pH value. Ammonium chloride $\left(\mathrm{NH}_{4} \mathrm{Cl}\right)$ was used as hardener (Tianjin Damao Chemical Reagent Factory).

And nine kinds of phosphorous nitrogen flame retardant chemicals were used in this study. Among them, six flame retardants were commercial, and three were synthesized in lab. The six commercial phosphorous nitrogenflame retardants are as follows: Pyrovatex $\mathrm{CP}$ (Ciba Chemical (China) Co., Ltd.), LM-Q (Qingdao Lianmei Chemical Co., Ltd.), SYHG (Sanyu Chemical (Shenzhen) Co., Ltd.), GUP (FQ-105A, Rufu City
Fuqaing Fire Retardant Co., Ltd.), LY (Liyi Dafang Wood Co., Ltd.), TL (Neimenggu Jinqiu Wood Co., Ltd.)

MCPR, UCPR, and bisDopo-NH $\mathrm{N}_{2}$-POSS (BDNP) (were synthesized in lab flame retardant. MCPR and UCPR are prepared with recation of Pyrovatex CP and urea or melamine. And the bisDopo- $\mathrm{NH}_{2}$-POSS is prepared using $\mathrm{NH}_{2}$-POSS and DOPO as raw materials. Totally, the nine kinds of flame retardant selected in this study are abbreviated as CP, LM-Q, SYHG, GUP, LY, TL, MCPR, UCPR and bisDopo- $\mathrm{NH}_{2}$-POSS (BDNP).

\subsection{Preparation of flame retardant adhesive}

All commercial flame retardants are in powder form. Among them, LM-Q flame retardant needs to be mixed and dissolved with water at a mass ratio of 1:1 (the rest of the flame retardants are added directly), and then added into the $\mathrm{E}_{0}, \mathrm{E}_{1}$ and $\mathrm{E}_{2}$ grade UF resin (UF is the polycondensation of urea and formaldehyde into the initial urea-formaldehyde resin under the action of the alkali-acid-alkali three-step reaction method (Lubis, M.A.R et al., 2019), and then under the action of a curing agent or auxiliary agent, an insoluble and insoluble final thermosetting resin is formed.) separately at a mass ratio of $5 \mathrm{wt} . \%$ based on liquid UF resin, and mixed together evenly. Then curing agent ammonium chloride $\left(\mathrm{NH}_{4} \mathrm{Cl}\right) \quad 1 \%$ and $10 \%-15 \%$ filler based on liquid UF resin was added, and it was stirred again.

\subsection{Preparation of flame retardant plywood}

UF resin was evenly applied to the first layer and the second layer on one side. The amount of adhesive on both sides is about $320 \mathrm{~g} / \mathrm{m}^{2}$. After aging for 8 minutes, hot pressing was performed at a temperature 
of $110^{\circ} \mathrm{C}$ with a unite pressure of $1.0 \mathrm{Mpa}$ for 180 seconds.

\subsection{Characterizations}

\subsubsection{FTIR}

A Perkin Elmer Spectrum $3^{\mathrm{TM}}$ FT-IR Fourier transform infrared spectrometer was used to perform FTIR analysis of UF (control), CP-UF, LM-Q-UF, TL-UF, MCPR-UF, UCPR-UF, and BDNP-UF. The above samples were dried until they reached a constant weight. After pressing the dry sample and $\mathrm{KBr}$ according to the mass ratio of $1: 100$, infrared scanning was performed. The spectrum range used was 500-4000 $\mathrm{cm}^{-1}$, the number of infrared scanning times was 32, and the resolution was $4.00 \mathrm{~cm}^{-1}$.

\subsubsection{Determination of adhesive curing time} According to GB/T 14074-2017 "Testing methods for wood adhesive and their resins", $50 \mathrm{~g}$ of the adhesive sample was put into a beaker, $0.5 \mathrm{~g}$ of ammonium chloride was added, and it was stirred evenly. Next, $10 \mathrm{~g}$ of all kinds of UF samples were put into a test tube and stirred with a rod. Then the test tube was put into a boiling water bath, and a stopwatch was immediately started. The adhesive sample in the test tube was $20 \mathrm{~mm}$ lower than the boiling level of the water bath. Under constant stirring, the sample gradually solidified, and the stopwatch recorded the time. Three replicates measurement were conducted.

\subsubsection{Determination of bonding strength of fire-retardant plywood}

According to the Chinese standard GB/T 9846-2015 "Plywood for general use" Type II plywood, the strength of the plywood sample was measured using a universal testing machine (MWW-10, Jinan Tianchen Testing Machine Manufacturing Co., Ltd.China). The sample was immersed in water for 24 hours at room

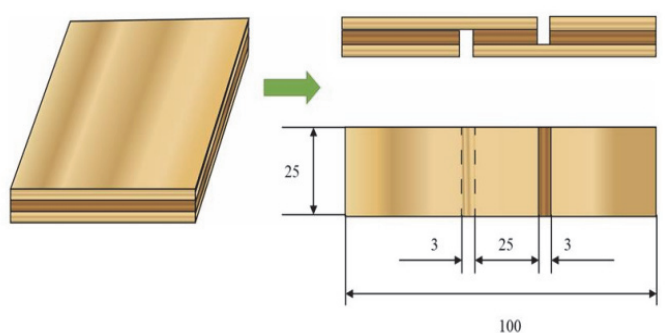

Fig. 1. Specimen in bonding strength test of plywood.

temperature or 3 hours at $63^{\circ} \mathrm{C} \pm 3^{\circ} \mathrm{C}$ for a wet bonding strength test. Then, it was air dried at room temperature for 10 minutes before testing. Each group of nine samples was prepared from every three plywood samples. The sample in the bond strength test is shown in Fig. 2. The bond strength $(\mathrm{MPa})$ was calculated by the following formula:

$$
\sigma=\frac{P_{M A X}}{\mathrm{~b} \times l}
$$

where, $\sigma$ : Bonding strength $(\mathrm{MPa})$

$P_{M A X}$ : The maximum failure $\operatorname{load}(\mathrm{N})$

$\mathrm{b}$ : The width of shear section $(\mathrm{mm})$

$l$ : The length of shear section $(\mathrm{mm})$

\subsubsection{Formaldehyde emission measurement results}

The formaldehyde emission of plywood was measured according to Chinese Standard GB 18580-2001 "Indoor decorating and refurbishing materials. Limit of formaldehyde emission of wood-based panels and finishing products", and the dryer device method is shown in the Fig. 2.

\subsubsection{Flame retardant test}

In this test, a butane spray gun with a maximum temperature of $1300^{\circ} \mathrm{C}$ was used to burn the center surface of the flame retardant plywood. Test was conducted in a closed and windless space. Fix the sample 


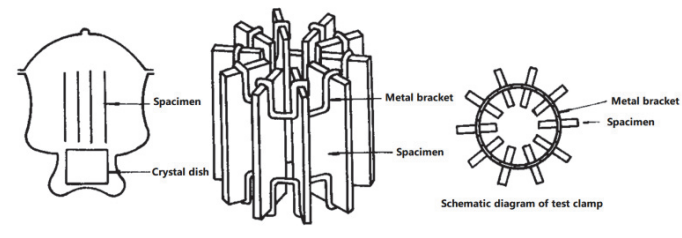

Fig. 2. Desiccator method of formaldehyde determination device.
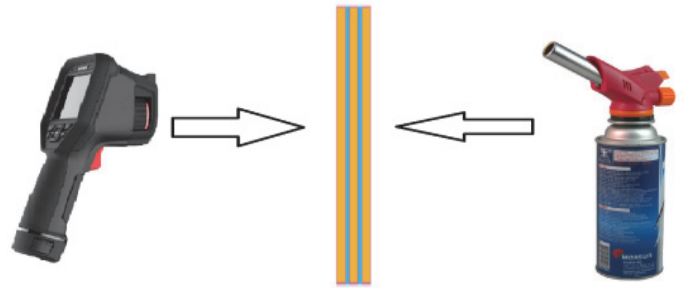

Fig. 3. Demonstration diagram of flame character test.

and the butane spray gun at the two ends of the joint $11.5 \mathrm{~cm}$. The samples $(15 \mathrm{~mm} \times 15 \mathrm{~mm} \times 3 \mathrm{~mm})$ were clamped with tweezers so that the angle between the sample surface and the vertical direction was 90 . The top of the flame was $0.5 \mathrm{~cm}$ away from the sample surface. The surface of the sample was perpendicular to the flame direction. The plywood samples were burn by outer flame of butane spray gun, and the flame length of the butane spray gun was set at 11 $\mathrm{cm}$. And then the burning of the wood was observed, including the temperature of the back of the plywood at $30 \mathrm{~s}, 60 \mathrm{~s}$ and $90 \mathrm{~s}$, and the instantaneous temperature when burning through. The temperature of the center point was recorded with a thermal imager.

\section{RESULTS and DISCUSSION}

\subsection{FTIR analysis}

FTIR is an effective method to test the success of flame retardant adhesives. Since $E_{2}$ flame retardant plywood is the widest variety of flame retardant ply-

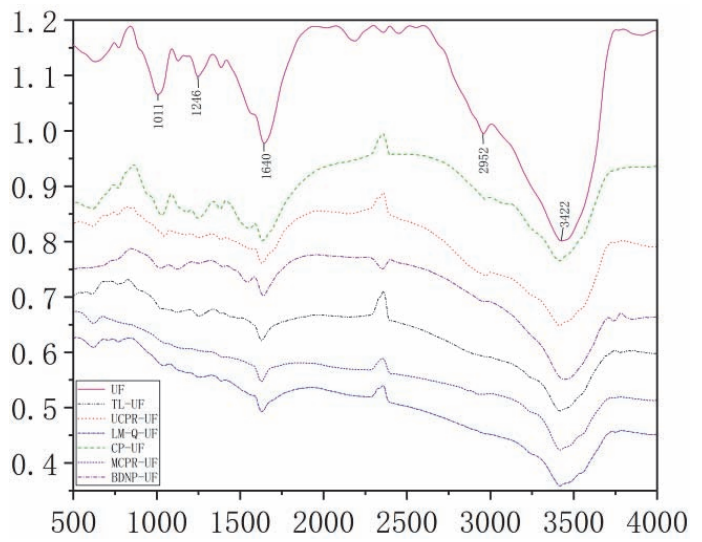

Fig. 4. Infrared spectra of flame retardant adhesives with qualified bonding strength of $E_{2}$.

wood with qualified adhesive strength, $\mathrm{E}_{2}$ grade flame retardant adhesive was selected for infrared spectroscopy scanning. The UF, TL-UF, LM-Q-UF, CP-UF, UCPR-UF, MCPR-UF and BDNP-UF types of flame retardant adhesive were tested (The bonding strength of those samples satisfied II type criterion). The C-O stretching vibration peak is at $1101 \mathrm{~cm}^{-1}$, and the $\mathrm{C}-\mathrm{N}$ absorption peak is at $1246 \mathrm{~cm}^{-1}$. However, all the flame retardant modified peaks at these two points are weakened to different degrees, which is due to the influence of the $\mathrm{P}$ element of the $\mathrm{PO}_{4}{ }^{3}$-functional group. $1640 \mathrm{~cm}^{-1}$ is the absorption peak of amide. $2952 \mathrm{~cm}^{-1}$ is the stretching vibration peak of the methylene group $\left(-\mathrm{CH}_{2}\right)$ in the urea-formaldehyde resin, and the stretching vibration peak of TL-UF disappears here. The broad absorption peaks in the range of 3100-3700 $\mathrm{cm}^{-1}$ are attributed to the stretching vibration peaks of the methyl $\left(-\mathrm{CH}_{2} \mathrm{OH}\right)$ and amino (-NH-) groups in the resin. The wide absorption band at $2000-2500 \mathrm{~cm}^{-1}$ is caused by the interaction between UF and phosphorus-nitrogen flame retardants to form hydrogen bonds. The new absorption peak at $498 \mathrm{~cm}^{-1}$ is the torsional absorption shock of the $\mathrm{NH}_{4}{ }^{+}$functional group, which proves that the $\mathrm{NH}_{4}{ }^{+}$in the phosphorus-nitrogen flame retardant is also combined with the UF resin molecule. 
The infrared spectra of TL-UF, UCPR-UF, CP-UF, LM-Q-UF, MCPR-UF and BDNP-UF are slightly different from UF. The weakening or disappearing of the peak indicates that the flame retardant has an effect on UF, resulting in a decrease in the bonding strength, but the main peak still exists.

\subsection{Adhesive curing time}

The curing time changed due to the addition of flame retardants. The curing times of flame retardant adhesives prepared with different flame retardants are shown in Fig. 5. Compared with UF resin (control), the curing time of TL-UF and LM-Q-UF are significantly increased. It is considered that LM-Q flame retardant needs to be solved in water before use, which increases the humidity of the environment where UF is cured. High humidity conditions accelerates the hydrolysis rate of methylol groups and methine ether bonds in the adhesive, which release formaldehyde and hinders the curing of the resin. Consequently the gel time was prolonged. In addition, TL flame retardant increased the $\mathrm{pH}$ value of UF resin, which also slowed down the curing speed and prolonged the cur- ing time. While BDNP-UF, GUP-UF, LY-UF and SYHG-UF are basically similar to UF resin (control). The addition of CP, UCPR and MCPR flame retardants make the curing time less than that of UF resin (control). Because CP, MCPR and UCPR contain a small amount of free formaldehyde. After the resin mixed with ammonium chloride $\left(\mathrm{NH}_{4} \mathrm{Cl}\right)$ curing agent, there needs to be enough free formaldehyde to react with ammonium chloride to accelerate curing. Therefore, the addition of CP, MCPR, and UCPR slightly shortened the gel time. However, the curing time of UF resin added BDNP flame retardant increased. The BDNP flame retardant synthesized in lab is hydrophobic, but UF is hydrophilic. Therefore cationic emulsifier hexadecyltrimethylammonium chloride was applied to increase the compatibility of BDNP flame retardant and UF resin. It is assumed that hexadecyltrimethylammonium chloride increases the molecular resistance between the UF resin components and reduces the collision between the reaction chain segments. Consequently, it is not easy for chemical cross-linking to occur. Therefore, the curing time becomes longer (Ma et al., 2006).

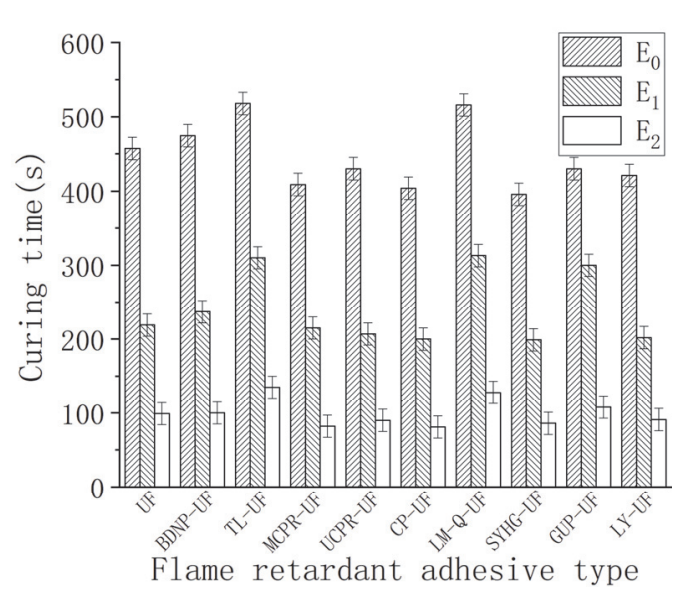

Fig. 5. The curing time of different types of flame retardant adhesives.

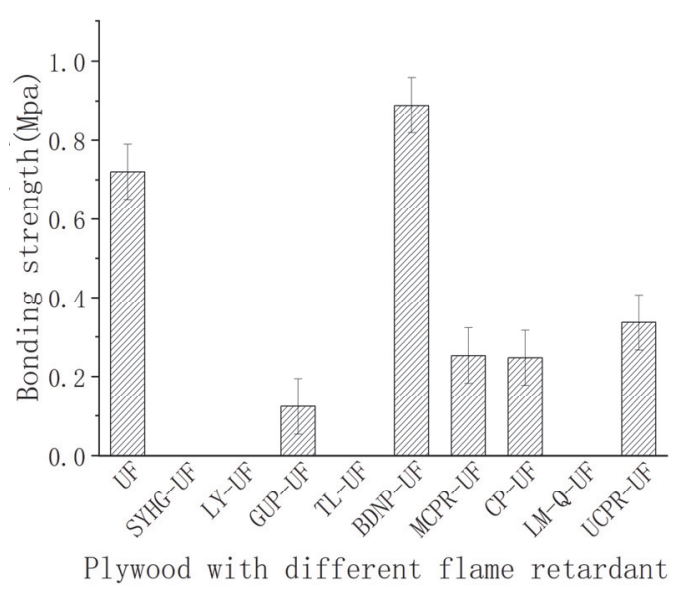

Fig. 6. $\mathrm{E}_{0}$ flame retardant plywood bonding strength (wet strength). 


\subsection{Bonding strength of plywood}

The bonding strength of $E_{0}$ grade UF plywood ( $E_{0}$ control) is $0.7152 \mathrm{Mpa}$. The addition of flame retardant has a greater impact on bonding strength of $\mathrm{E}_{0}$ grade plywood. It can be seen in Fig. 6 that only the $\mathrm{E}_{0}$ flame retardant plywood with BDNP (bisDopo- $\mathrm{NH}_{2}$-POSS, one of three flame retardant synthesized in lab) added meets the requirements of the II type board, and even exceeds the bonding strength of the control. The flame retardant BDNP (bisDOPO- $\mathrm{NH}_{2}$-POSS) is composed of a polyhedral oligomer composed of silsesquioxane (POSS) and two units 9,10-dihydro-9- oxa-10-phosphaphenanthrene10-oxide (DOPO) build a phosphorus-silicon-nitrogen synergistic system. It is considered that the amino group $\left(-\mathrm{NH}_{2}\right)$ of BDNP reacted with the methyl group $\left(-\mathrm{CH}_{2} \mathrm{OH}\right)$ in UF resin, which can also increase the second polycondensation and form a hyper-branched structure. Consequently the bonding strength was improved. The $\mathrm{E}_{1}$ plywood control board has a bonding strength of $0.879 \mathrm{Mpa}$. Among the $\mathrm{E}_{1}$ flame retardant plywood, there are four flame retardant plywood that can meet the standards of II type board.

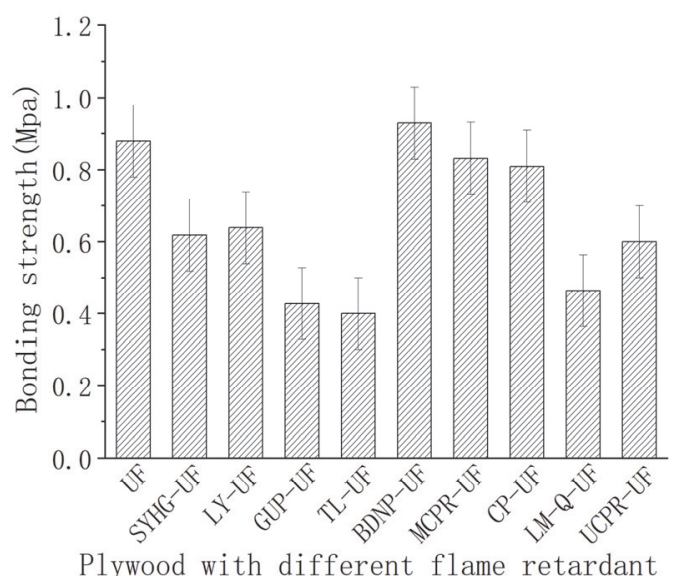

Fig. 7. $E_{1}$ flame retardant plywood bonding strength (wet strength).
The bonding strength of BDNP-UF, MCPR-UF, CP-UF is $0.93 \mathrm{Mpa}, 0.832 \mathrm{Mpa}$, and $0.81 \mathrm{Mpa}$, respectively.

The bonding strength of $\mathrm{E}_{2}$ grade UF plywood (control) is $1.24 \mathrm{Mpa}$. Among flame retardant plywood, the bonding strength of BDNP-UF, TL-UF, MCPR-UF, CP-UF, LM-Q-UF and UCPR-UF are all above $0.7 \mathrm{Mpa}$. The addition of TL, MCPR, CP, LM-Q and UCPR flame retardants decreased the bonding strength slightly, but they all meet the corresponding national standards of China. LU et al. (2021) also adopted a method of adding an appropriate amount of flame retardant to the adhesive. When the flame retardant content in the adhesive reaches $10 \%$, the bonding strength begins to drop significantly, and the bonding strength of most flame retardant plywood does not meet the requirements of Type II plywood (Chinese National Standard GB/T19846-2015 "Plywood for general use").

\subsection{Formaldehyde emission}

The World Health Organization lists formaldehyde as a category 1 carcinogen. Many countries control the

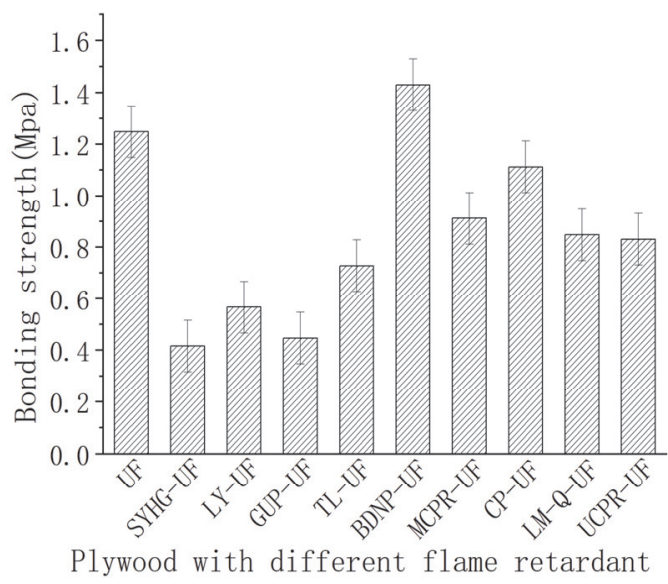

Fig. 8. $E_{2}$ flame retardant plywood bonding strength (wet strength). 
Yang LIU $\cdot$ Jun-xian XU $\cdot$ Ming-yu WEN $\cdot$ Hee-Jun PARK3 $\cdot$ Jia-zhi ZHU $\cdot$ Yu-nan LIU

Table 1. Amount of formaldehyde release of flame retardant $E_{0}$ environmental urea-formaldehyde resin

\begin{tabular}{ccc}
\hline Plywood type & Formaldehyde emission $(\mathrm{mg} / \mathrm{L})$ & Limit determination \\
\hline \hline UF & 0.345 & Meet $\mathrm{E}_{0}$ standard \\
BDNP-UF & 0.465 & Meet $\mathrm{E}_{0}$ standard \\
\hline
\end{tabular}

Table 2. Amount of formaldehyde release of flame retardant $E_{1}$ environmental urea-formaldehyde resin

\begin{tabular}{ccc}
\hline Plywood type & Formaldehyde emission $(\mathrm{mg} / \mathrm{L})$ & Limit determination \\
\hline \hline UF & 0.410 & Meet $\mathrm{E}_{1}$ standard \\
BDNP-UF & 0.672 & Meet $\mathrm{E}_{1}$ standard \\
CP-UF & 0.355 & Meet $\mathrm{E}_{1}$ standard \\
MCPR-UF & 0.754 & Meet $\mathrm{E}_{1}$ standard \\
\hline
\end{tabular}

Table 3. Amount of formaldehyde release of flame retardant $E_{2}$ environmental urea-formaldehyde resin

\begin{tabular}{ccc}
\hline Plywood type & Formaldehyde emission $(\mathrm{mg} / \mathrm{L})$ & Limit determination \\
\hline \hline UF & 1.560 & Meet $\mathrm{E}_{2}$ standard \\
BDNP-UF & 1.073 & Meet $\mathrm{E}_{2}$ standard \\
CP-UF & 1.335 & Meet $\mathrm{E}_{2}$ standard \\
MCPR-UF & 1.194 & Meet $\mathrm{E}_{2}$ standard \\
UCPR-UF & 1.024 & Meet $\mathrm{E}_{2}$ standard \\
TL-UF & 1.169 & Meet $\mathrm{E}_{2}$ standard \\
LM-Q-UF & 0.989 & Meet $\mathrm{E}_{2}$ standard \\
\hline
\end{tabular}

Table 4. Thermal imaging combustion experiment comparison table

\begin{tabular}{c|c|c|c|c}
\hline \multirow{2}{*}{$\begin{array}{r}\text { Plywood type } \\
\text { times(s) }\end{array}$} & $\begin{array}{c}\text { Central point } \\
\text { burning }\end{array}$ & $\begin{array}{c}\text { Central point } \\
\text { burning }\end{array}$ & $\begin{array}{c}\text { Central point } \\
\text { burning }\end{array}$ & Central point burning \\
\cline { 2 - 5 } & 30 & 60 & 90 & Burn-through time \\
\hline \hline UF & $<100^{\circ} \mathrm{C}$ & $212^{\circ} \mathrm{C}$ & $/$ & $392^{\circ} \mathrm{C}(72 \mathrm{sec})$ \\
\hline UCPR-UF & $<100^{\circ} \mathrm{C}$ & $121^{\circ} \mathrm{C}$ & $268^{\circ} \mathrm{C}$ & $437^{\circ} \mathrm{C}(96 \mathrm{sec})$ \\
\hline MCPR-UF & $<100^{\circ} \mathrm{C}$ & $127^{\circ} \mathrm{C}$ & $259^{\circ} \mathrm{C}$ & $468^{\circ} \mathrm{C}(99 \mathrm{sec})$ \\
\hline BDNP-UF & $<100^{\circ} \mathrm{C}$ & $111^{\circ} \mathrm{C}$ & $179^{\circ} \mathrm{C}$ & $434^{\circ} \mathrm{C}(109 \mathrm{sec})$ \\
\hline TL-UF & $<100^{\circ} \mathrm{C}$ & $116^{\circ} \mathrm{C}$ & $264^{\circ} \mathrm{C}$ & $449^{\circ} \mathrm{C}(97 \mathrm{sec})$ \\
\hline LM-Q-UF & $<100^{\circ} \mathrm{C}$ & $117^{\circ} \mathrm{C}$ & $221^{\circ} \mathrm{C}$ & $479^{\circ} \mathrm{C}(100 \mathrm{sec})$ \\
\hline $\mathrm{CP}-U F$ & $<100^{\circ} \mathrm{C}$ & $156^{\circ} \mathrm{C}$ & $391^{\circ} \mathrm{C}$ & $391{ }^{\circ} \mathrm{C}(90 \mathrm{sec})$ \\
\hline
\end{tabular}

emission or daily intake of formaldehyde (Han et al., 2019). The generation of free formaldehyde is due to the gradual hydrolysis of the urea-formaldehyde resin in the reverse reaction. Since the bonding strength of
$\mathrm{E}_{0}, \mathrm{E}_{1}$ and $\mathrm{E}_{2}$ flame retardant plywood determines the qualified flame retardant plywood type, only the formaldehyde emission of flame retardant plywood with qualified bonding strength were determined. The 

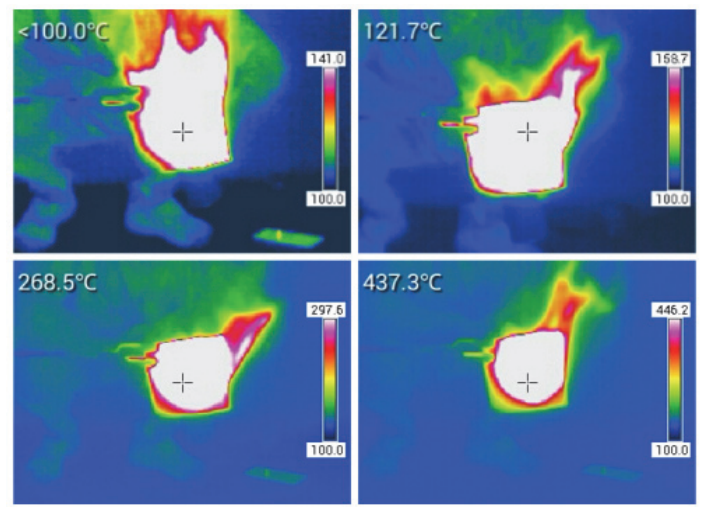

Fig. 9. Thermal image of UCPR flame retardant plywood.
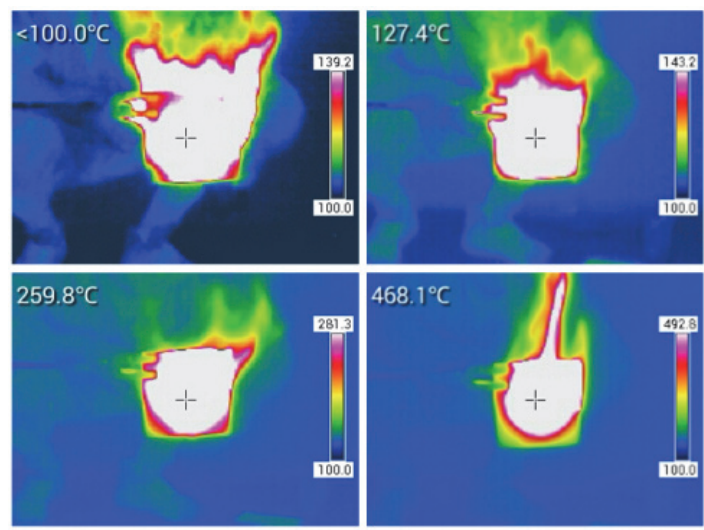

Fig. 10. Thermal image of MCPR flame retardant plywood.
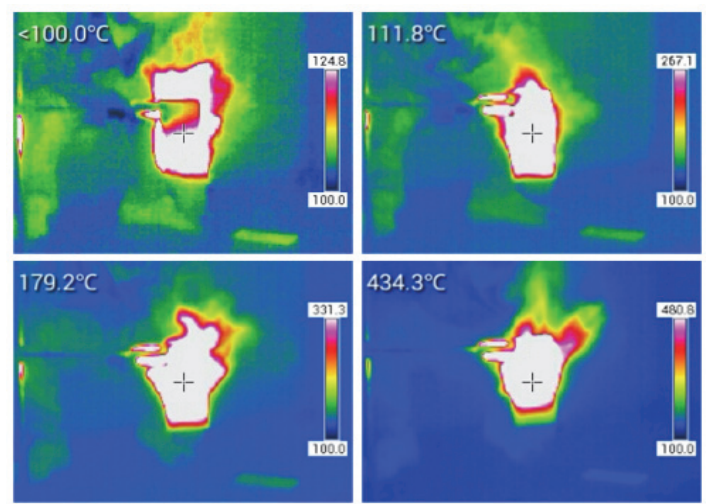

Fig. 11. Thermal image of BDNP flame retardant plywood. chemical reaction between the flame retardant and the free formaldehyde in the UF resin system affects the amount of formaldehyde released. Because polyoxymethylene (POM) is involved in the preparation of BDNP, it caused a small increase in the amount of formaldehyde released, but it still meets the requirements of the national standard for $E_{0}, E_{1}$, or $E_{2}$ ply wood with UF resin, respectively. According to Chinese Standard GB 18580-2001 "Indoor decorating and refurbishing materials limit of formaldehyde emission of wood-based panels and finishing products", the formaldehyde emission of all the above flame retardant urea-formaldehyde resins with qualified bonding strength are all qualified.

\subsection{Flame retardant test}

In Table 4, it can be seen that the temperature rise of flame retardant plywood (between $30 \mathrm{sec}$. and 60 sec.) is much lower than that of control plywood (UF resin without flame retardant). And the maximum difference can reach $101^{\circ} \mathrm{C}$ at $60 \mathrm{sec}$. Meanwhile, the burn-through time is also extended by at least $25 \%$, which proves that flame retardant plywood has certain flame retardant properties. In order to show the flame retardant performance of the laboratory-made flame retardant, Fig. 9, Fig. 10, and Fig. 11 show thermal images of UCPR, MCPR and BDNP at $30 \mathrm{sec}$., 60 sec., $90 \mathrm{sec}$. and the time of burning through during the flame retardant test.

\section{CONCLUSION}

In this study, six commercial and three laboratory synthesized phosphorous nitrogen flame retardants, and $E_{0}, E_{1}$ and $E_{2}$ grade commercial UF resins were selected to prepare flame retardant plywood. The influence of flame retardant on the UF resin curing time, bonding strength, formaldehyde emission and flame 
retardant performance of plywood were evaluated.

(1) According to Chinese Standard GB/T 9846-2015 "Plywood for general use", the following bonding strength results were obtained: one flame retardant (BDNP) was determined to meet the adhesive strength of $\mathrm{E}_{0}$ plywood; three flame retardants, BDNP, MCPR and $\mathrm{CP}$, were determined to be qualified for the bonding strength of $\mathrm{E}_{1}$ plywood; and six flame retardants, BDNP, MCPR, CP, UCPR, TL and LM-Q, were qualified for the bonding strength of $E_{2}$ plywood.

(2) In $E_{0}$ grade UF, the addition of flame retardant has a more obvious effect on curing time. However, as the molar ratio of formaldehyde to urea increasing, the effect of adding flame retardants on the curing time gradually decreases. In $\mathrm{E}_{1}$ grade UF, TL, LM-Q and GUP have a greater impact on the curing time. In $\mathrm{E}_{2}$ grade UF only TL and the two flame retardants LM-Q have a relatively obvious effect on the curing time.

(3) According to Chinese Standard GB 18580-2001 "Indoor decorating and refurbishing materials Limit of formaldehyde emission of wood-based panels and finishing products", the free formaldehyde emission of TL, CP, UCPR, MCPR, BDNP and LM-Q flame retardant plywood meets the $\mathrm{E}_{0} / \mathrm{E}_{1} / \mathrm{E}_{2}$ level standard, respectively $\left(\mathrm{E}_{0} \leq 0.5 \mathrm{mg} / \mathrm{L}, \mathrm{E}_{1} \leq 1.5 \mathrm{mg} / \mathrm{L}, \mathrm{E}_{2} \leq 5\right.$ $\mathrm{mg} / \mathrm{L})$.

(4) In the flame retardant test, it was found that the plywood with flame retardant added had a greater improvement in flame retardancy compared with the control plywood. Although the flame retardancy of plywood is improved, no suitable phosphorous nitrogen flame retardant has been found that has little negative effect on the plywood performance of low-formaldehyde plywood $\left(\mathrm{E}_{0}\right)$ and formaldehyde-free plywood. The hygroscopicity of flame retardant plywood and smoke suppression properties during the combustion process are not discussed in this study, and further research is needed.

\section{ACKNOWLEDGMENT}

The authors are grateful for the support of the National Natural Science Foundation of China (31700483), the Excellent young talents project of Department of science and technology of Jilin Province (20190103111JH) and the Youth Science and Technology Innovation Team Cultivation Program of Beihua University "Innovation Team of Wood Material Functional Modification" 2020.

Also thanks to the support of 'R\&D Program for Forest Science Technology (Project No. FTIS 2020223A00-2122-AC02)' provided by Korea Forest Service (Korea Forestry Promotion Institute).

\section{REFERENCES}

Chen, J., Yu, L.P., Tian, M.F., Wang, Y., Long, Z.Y. 2020. Effect of compound flame retardant on the properties of poplar plywood. China Forest Products Industry 57(1): 22-24.

Cheng, R.X. 2008. Study on processing technology of wear-resisted sliced veneer facing board. China Wood-Based Panels (6): 32-34.

Dou, W.-H., Liu, D.-Y., Wang, W.-T., Zhao, B., Liu, Y.-Q. 2016. Synthesis of a new type of P-N-Si halogen-free flame retardant and its application in cotton fiber. Chinese Journal of Synthetic Chemistry 24(2): 107-111.

GB 18580-2001. "Indoor decorating and refurbishing materials Limit of formaldehyde emission of wood-based panels and finishing products".

Han, H.J., Lee, S.E., Yang, S.M., Choi, C., Kang, S.G. 2019. Evaluation of formaldehyde emission from wood-based panels using accelerated collection method. Journal of the Korean Wood Science and Technology 47(2): 129-144.

Jeong, B., Park, B.D. 2019. Performance of urea-formaldehyde resins synthesized at two 
different low molar ratios with different numbers of urea addition. Journal of the Korean Wood Science and Technology 47(2): 221-228.

LeVan, S.L., Winandy, J.E. 1990. Effects of fire retardant treatments on wood strength: A review. Wood and Fiber Science 22(1): 113-131.

Ling, Z.G., Omura, Y., Hori, N., Iwata, T., Takemura, A. 2018. In-situ chemical structure analysis of aqueous vinyl polymer solution-isocyanate adhesive in post-cure process by using Fourier transform near infrared spectroscopy. International Journal of Adhesion and Adhesives 81: 56-64.

Lu, S.Y., Hamerton, I. 2002. Recent developments in the chemistry of halogen-free flame retardant polymers. Progress in Polymer Science 27(8): 1661-1712.

Lu, Y.H., Zhang, Y., Zhang, S., Huang, Y.P., Pan, M.Z. 2021. Preparation of flame-retardant plywood by PEI /APP modified urea-formaldehyde resin and its properties. Journal of Forestry Engineering 6(1): 44-49.

Lubis, M.A.R, Jeong, B., Park, B.D., Lee, S.M., Kang, E.C. 2019. Effect of synthesis method and melamine content of melamine-urea-formaldehyde resins on bond-line features in plywood. Journal of the Korean Wood Science and Technology 47(5): 579-586.

Lubis, M.A.R., Park, B.D., Lee, S.M. 2019. Performance of hybrid adhesives of blocked-pMDI/melamine-ureaformaldehyde resins for the surface lamination on Plywood. Journal of the Korean Wood Science and Technology 47(2): 200-209.

Ma, S.M., Liu, J.S., Liu, C.P., Jiang, W., Wang, Y.F. 2006. Study on curing reaction of urea formaldehyde resign. Chemical Engineer 11: 53-54.

Pan, J., Jia, L,W., Liu, R. 2019. Research progress on the synergistic effect of phosphorus-containing flame retardants. Textile Auxiliaries 38(6): 7-8.

Park, S.H., Han, Y.J., Son, D.W. 2021. Flame retardancy of plywood treated with various water glass concentration and additives. Journal of the Korean Wood Science and Technology 49(1): 44-56.

Park, S.H., Han, Y.J., Song, D.W. 2020. Flame retardancy of wood products by spreading concentration and impregnation time of flame retardant. Journal of the Korean Wood Science and Technology 48(4): 417-430. Qian, X.D., Song, L., Yuan, B.H., Yu, B., Shi, Y.Q., Hu, Y., Yuen, R.K.K. 2014. Organic/inorganic flame retardants containing phosphorus, nitrogen and silicon: Preparation and their performance on the flame retardancy of epoxy resins as a novel intumescent flame retardant system. Materials Chemistry and Physics 143(3): 1243-1252.

Qian, Y., Wei, P., Jiang, P.K., Hao, J.W., Du, J.X. 2013. Preparation of hybrid phosphamide containing polysilsesquioxane and its effect on flame retardancy and mechanical properties of polypropylene composites. Composites Part B Engineering 45(1): 1541-1547.

Qin, L., Liu, X.H., Zhang Z.T. 2020. Current status and development trend of my country's plywood industry. China Forest Products Industry 57(11): 1-3.

Qu, L.J, Sui, Y.L., Zhang, C.L., Dai, X.Y., Li, P.H., Sun, G.E., Xu, B.S., Fang, D.N. 2020. Improved flame retardancy of epoxy resin composites modified with a low additive content of silica-microencapsulated phosphazene flame retardant. Reactive and Functional Polymers 148(2020): 104485.

Tan, H.B. 2020. Current status and trends of international trade in china's major wood products. China Forest Products Industry 57(1): 75-76,79.

Wang, H.J., Chen, L.X., Miao, H. 2005. General situation of research and application of nitrogen flame retardants. THERMOSETTING RESIN 20(4): 36-41.

Wang, H.Y., Cao, P.X., Wang, J., Li, J.Y., Liang, X.Y. 2016. Research and analysis of flame retardant recombinant wood. FOREST ENGINEERING 32(3): 48-52. 
Wang, S., Sui, X.F., Li, Y.Z., Li, J.W., Xu, H., Zhong, Y., Zhang, L.P., Mao, Z.P. 2016. Durable flame retardant finishing of cotton fabrics with organosilicon functionalized cyclotriphosphazene. Polymer Degradation and Stability 128: 22-28.

Wang, W., Zammarano, M., Shields, J.-R., Knowlton E.-D. 2018. A novel application of silicone-based flame-retardant adhesive in plywood. Construction and Building Materials 189: 448-459.

Wang, Y.C., Zhao, J.P. 2018. Preliminary study on decanoic/palmitic eutectic mixture modified silica fume geopolymer-based coating for flame retardant plywood. Construction and Building Materials 189: $1-7$.

Wen, M.Y., Zhu, J.Z., Zhu, M., Sun, Y.X., Park, H.J., Shi, J.Y. 2020. Research on flame retardant formaldehyde-free plywood glued by aqueous polymer isocyanate adhesive. Journal of the Korean Wood Science and Technology 48(5): 755-764.

Winandy, J.E., Schmidt, E.L. 1995. Preliminary development of remedial treatments for thermally degraded fire-retardant-treated wood. Forest Products Journal 45(2): 51-52.

Yan, L., Xu, Z., Wang, X. 2018. Synergistic effects of organically modified montmorillonite on the flame-retardant and smoke suppression properties of transparent intumescent fire retardant coatings. Progress in Organic Coatings 122: 107-118.

Yang, Z.Y., Fei, B., Wang, X.W., Xin, J.H. 2012. A novel halogen-free and formaldehyde-free flame retardant for cotton fabrics. Fire and Materials 36(1): 31-39. 